\title{
Research Article \\ Effects of CFRP Strengthening on Dynamic and Fatigue Responses of Composite Bridge
}

\author{
Kittisak Kuntiyawichai ${ }^{1}$ and Suchart Limkatanyu ${ }^{2}$ \\ ${ }^{1}$ Department of Civil Engineering, Faculty of Engineering, Ubon Ratchathani University, Ubon Ratchathani 34190, Thailand \\ ${ }^{2}$ Department of Civil Engineering, Faculty of Engineering, Prince of Songkla University, Songkhla 90112, Thailand \\ Correspondence should be addressed to Kittisak Kuntiyawichai; kittisak.ubu@gmail.com
}

Received 5 November 2013; Accepted 21 January 2014; Published 7 April 2014

Academic Editor: Mohd Sapuan Salit

Copyright @ 2014 K. Kuntiyawichai and S. Limkatanyu. This is an open access article distributed under the Creative Commons Attribution License, which permits unrestricted use, distribution, and reproduction in any medium, provided the original work is properly cited.

\begin{abstract}
This paper investigates the effect of CFRP strengthening on dynamic and fatigue responses of composite bridge using finite element program ABAQUS. Dynamic and fatigue responses of composite bridge due to truck load based on AASHTO standard are investigated. Two types of CFRP strengthening techniques, CFRP sheets and CFRP deck, are applied to both the damaged and undamaged bridges. For the case of damaged bridge, two through-thickness crack sizes, $3 \mathrm{~mm}$ and $6 \mathrm{~mm}$ in depth, are assumed at midspan of the steel girders. Furthermore, effects of the number of steel girders on the dynamic and fatigue responses are also considered. The results show that the maximum responses of composite bridges occur for dual lane cases. By using CFRP as a strengthening material, the maximum stress and deflection of the steel girders reduce and consequently increase the fatigue life of the girders. After introducing initial crack into the steel girders of the composite bridges, the fatigue life of the bridges is dramatically reduced. However, the overall performance of the damaged composite bridge can be improved by using CFRP, albeit with less effectiveness. Therefore, if cracks are found, steel welding must be performed before strengthening the composite bridge by CFRP.
\end{abstract}

\section{Introduction}

In the past 50 years, many types of bridges have been introduced in order to serve traffic growths. Due to advantage in construction time, as well as effectiveness, composite bridge appears to be one of the most popular bridge types which is widely adopted throughout the world. The main components of a composite bridge are decks constructed of reinforced concrete and supported by longitudinal steel girders. However, because of their normal deterioration, introduction of new safety standards, and increasing traffic volume and loads, a high percentage of older bridges require rehabilitation or reconstruction. Often, the choice between constructing a new bridge and rehabilitating an existing one must be made.

In most cases, rehabilitating existing bridges is more cost-effective than replacement and can be accomplished in a shorter period of time with less inconvenience to the traveling public. Various methods have been used in the past to strengthen steel bridges $[1,2]$. One method used in the past on steel bridges is the bonding of steel plates to the tension flange of the girders. However, this method has several disadvantages, including difficulties in installing heavy steel plates at the bridge site, as well as the limited length of a plate that can be delivered to the site. In general, conventional strengthening techniques are labor intensive and disruptive to traffic flows.

Since 1990, application of carbon fiber reinforced polymer (CFRP) in strengthening civil engineering structures has become an attractive retrofit practice. The main advantages of CFRP in general for CFRP sheets are their high strength/weight and stiffness/weight ratios, high degree of chemical inertness in most civil engineering environments, and their nonmagnetic and nonconductive properties [3]. According to some previous research works on the use of CFRP sheets to repair and strengthen existing composite bridges, several researchers have conducted experimental tests on individual steel girders strengthened with CFRP under static loadings [4-6]. They have reported that CFRP 
sheets could significantly increase the ultimate load carrying capacity of intact girders and restore the ultimate load carrying capacity and stiffness of damaged composite girders. Tavakkolizadeh and Saadatmanesh [7] studied the fatigue behavior of both damaged and undamaged steel beams retrofitted with epoxy bonded CFRP. They have found that CFRP sheets not only tend to extend the fatigue life of a bridge more than three folds but also decreases the crack growth rate significantly. Miller et al. [8] demonstrated the use of CFRP in the field by strengthening a steel girder in a composite bridge. They found that the measured strain at the tension face of the steel girder reduced. For the case of replacing an old deteriorated concrete deck of a truss bridge with CFRP deck, an experimentally validated finite element (FE) model has been investigated $[9,10]$. It was found that the fatigue life of the bridge after rehabilitation was doubled when compared to a prerehabilitated reinforced concrete deck system. From the above literatures, no study on the overall fatigue behavior of a composite bridge retrofitted with CFRP was noted. Hence, the effect of CFRP strengthening on the overall fatigue behavior of composite bridges is investigated in this paper.

The main objective of this paper is to investigate the effect of CFRP strengthening on the dynamic and fatigue responses of composite bridge using FE program ABAQUS. In the analysis process, dynamic behaviors and fatigue responses due to varied direction of moving truck load based on AASHTO standard are investigated. Two types of CFRP strengthening techniques, CFRP sheets and CFRP deck, are applied to both damaged and undamaged bridges. For the case of damaged bridges, two through-thickness crack sizes, $3 \mathrm{~mm}$ and $6 \mathrm{~mm}$ in depth, are assumed at midspan of the steel girders. Furthermore, the effect of the number of steel girders on the dynamic behavior and fatigue responses are also investigated.

\section{Description of a Composite Bridge}

The prototype bridge on which the analyses are based is a simple span composite bridge. AASHTO LRFD Bridge Design Specifications [11] were employed to design the prototype bridge in accordance with HS-20 notation live load. Material properties used for the design are shown in Table 1. The bridge is $9.93 \mathrm{~m}$ wide and has a length of $18 \mathrm{~m}$, as shown in Figure 1.

The doubly reinforced RB9@0.10m concrete deck is supported by three steel girders with a spacing of $4.63 \mathrm{~m}$. Figure 2 shows the cross-section of the bridge, including the girders, diaphragms, and parapets.

The welded I-section girders have a depth of $1.2 \mathrm{~m}$, a web thickness of $0.016 \mathrm{~m}$, a flange thickness of $0.040 \mathrm{~m}$, and a flange width of $0.5 \mathrm{~m}$. The top flanges of the girders are attached to the reinforced concrete deck with shear studs. Diaphragms are joined at the centre and both ends of the girders. In order to study the effect of the number of steel girders on the dynamic behavior and fatigue strength, the number of steel girders of the above bridge is reassigned to be 5 .
TABLE 1: Material properties of the prototype bridge.

\begin{tabular}{lcc}
\hline Component & Properties & Value \\
\hline \multirow{3}{*}{ Steel girder } & Density & $7850 \mathrm{~kg} / \mathrm{m}^{3}$ \\
& Modulus of elasticity & $200 \mathrm{GPa}$ \\
& Poisson's ratio & 0.3 \\
\hline \multirow{3}{*}{ RC steel } & Density & $7850 \mathrm{~kg} / \mathrm{m}^{3}$ \\
& Modulus of elasticity & $200 \mathrm{GPa}$ \\
& Poisson's ratio & 0.3 \\
\hline \multirow{3}{*}{ Diaphragm } & Density & $7850 \mathrm{~kg} / \mathrm{m}^{3}$ \\
& Modulus of elasticity & $200 \mathrm{GPa}$ \\
& Poisson's ratio & 0.3 \\
\hline \multirow{3}{*}{ Concrete } & Density & $2400 \mathrm{~kg} / \mathrm{m}^{3}$ \\
& Modulus of elasticity & $28.6 \mathrm{GPa}$ \\
& Poisson's ratio & 0.2 \\
\hline
\end{tabular}

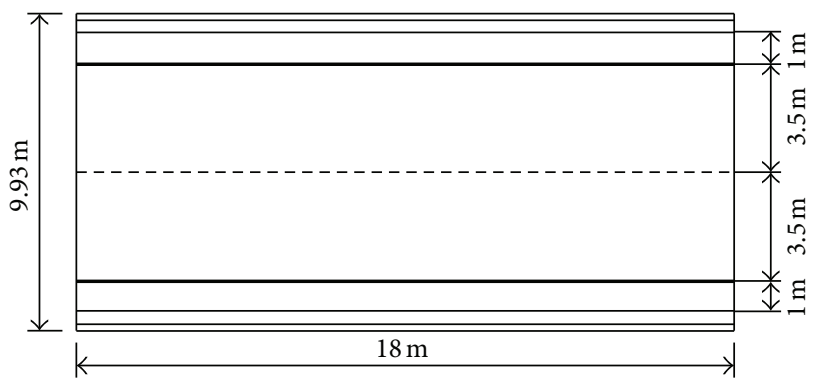

Figure 1: Plan view of the bridge.

\section{Finite Element Model and Verifications}

A finite element model of the composite bridge was developed using ABAQUS finite element software [12].

3.1. Model Descriptions. The concrete deck, steel girders, and diaphragms are modeled with three-dimensional shell elements. Shell elements are used when the thickness dimension is significantly less than the other two dimensions. Conventional shell elements have six degrees of freedom, three for displacement and three for rotation. S4R elements are used to model the deck. This is a conventional four node, quadrilateral, stress/displacement shell element with reduced integration and a large strain formulation. It is a rectangularshaped element with a node at each corner. The properties of the section are calculated by using the shell section option. This uses numerical integration through the thickness of the shell and is suited for solving nonlinear problems, in this case the analysis of a reinforced concrete deck. In this option the thickness of the shell and the number of integration points are defined.

Once all the parts have been modeled and the section properties for each have been defined, the next step is to assemble these parts together using contact element. This allows forces and moments to transfer between parts. Figure 3 shows the FE model of the composite bridges.

For the case of composite bridge strengthened by CFRP sheets, CFRP sheets attaching to the bottom flanges of the 


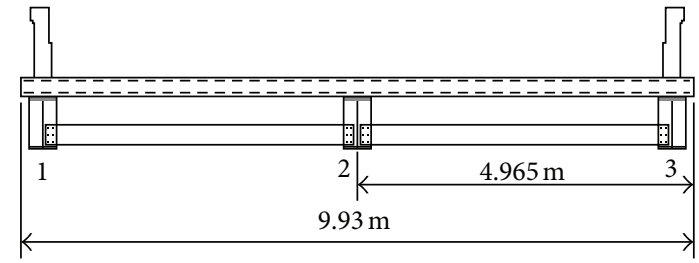

(a) 3 girders

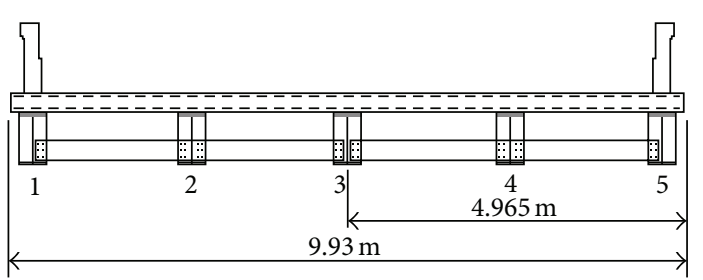

(b) 5 girders

FIGURE 2: Cross-sections of the composite bridges.

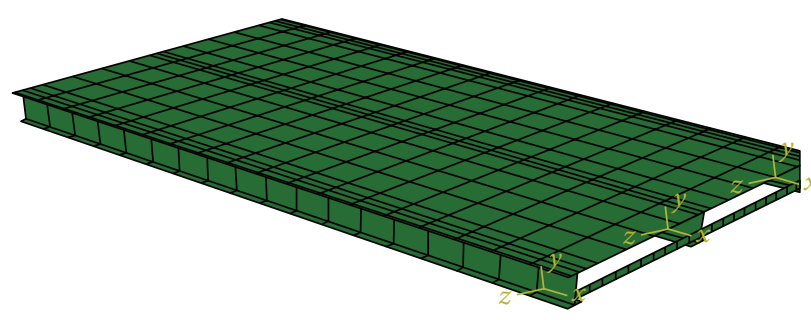

(a) 3 girders

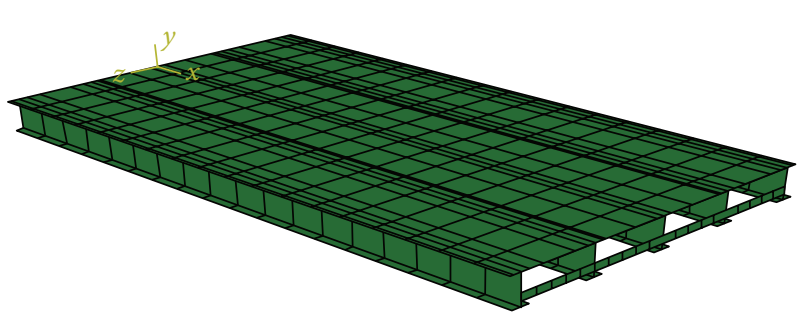

(b) 5 girders

FIgURE 3: Finite element model of the composite bridges.

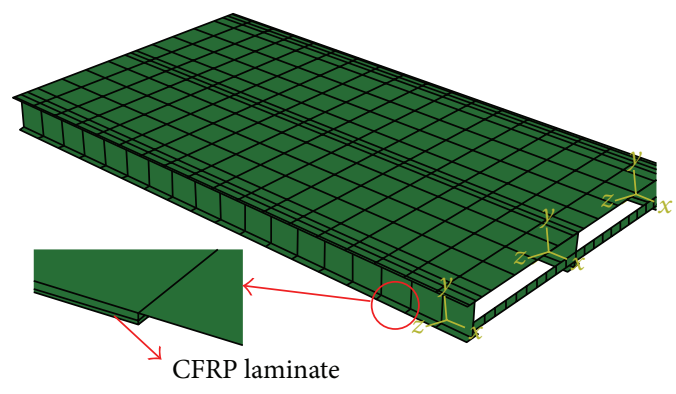

(a) 3 girders

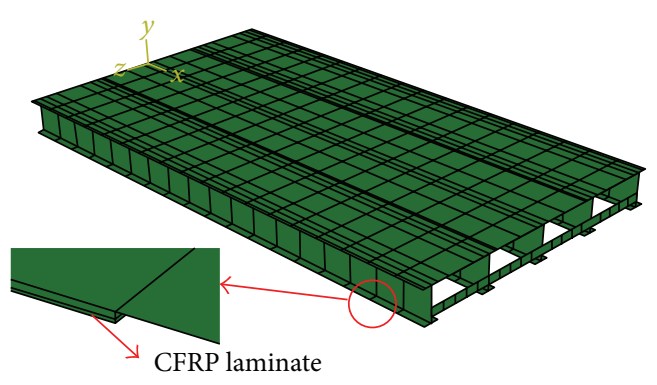

(b) 5 girders

FIGURE 4: Finite element model of the composite bridges with CFRP laminate.

steel girders are modeled using 3-dimensional solid element, namely, C3D8R. The thickness and the width of CFRP sheets are $1.4 \mathrm{~mm}$ and $0.5 \mathrm{~m}$, respectively. Special adhesive elements which are useful in modeling adhesives and bonded interfaces, namely, COH3D8 available in ABAQUS, are adopted into the FE model at the $3 \mathrm{~mm}$ thickness interfaces between the steel surface and CFRP sheets. For the case of composite bridge strengthened by changing concrete bridge deck to a CFRP composite deck, the CFRP deck panels are modeled as a sandwich-typed construction, using S4R elements, consisting of top and bottom face skins and a core component. Each cell of the cubic CFRP block has a dimension of $25 \mathrm{~cm} \times$ $25 \mathrm{~cm} \times 25 \mathrm{~cm}$. The thickness of top and bottom face skins and a core component is $1 \mathrm{~cm}$. Figures 4 and 5 show the FE model of the strengthened composite bridges.

Material properties assigned to the FE model are summarized in Tables 1 and 2.
TABle 2: Properties of special materials.

\begin{tabular}{lcc}
\hline Component & Properties & Value \\
\hline \multirow{3}{*}{ FRP composite deck } & Density & $1800 \mathrm{~kg} / \mathrm{m}^{3}$ \\
& Modulus of elasticity & $19.3 \mathrm{Gpa}$ \\
& Poisson's ratio & 0.33 \\
& Max. tension stress & $207 \mathrm{Mpa}$ \\
& Max. comp. stress & $207 \mathrm{Mpa}$ \\
\hline FRP laminate & Density & $1500 \mathrm{~kg} / \mathrm{m}^{3}$ \\
& Modulus of elasticity & $165 \mathrm{Gpa}$ \\
& Poisson's ratio & 0.30 \\
& Max. tension stress & $2.80 \mathrm{Gpa}$ \\
\hline \multirow{3}{*}{ Adhesive } & Density & $1770 \mathrm{~kg} / \mathrm{m}^{3}$ \\
& Modulus of elasticity & $12.8 \mathrm{Gpa}$ \\
& Poisson's ratio & - \\
& Max. tension stress & $33 \mathrm{Mpa}$ \\
\hline
\end{tabular}




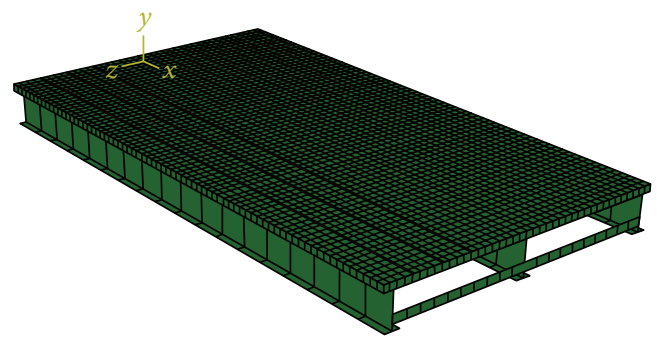

(a) 3 girders

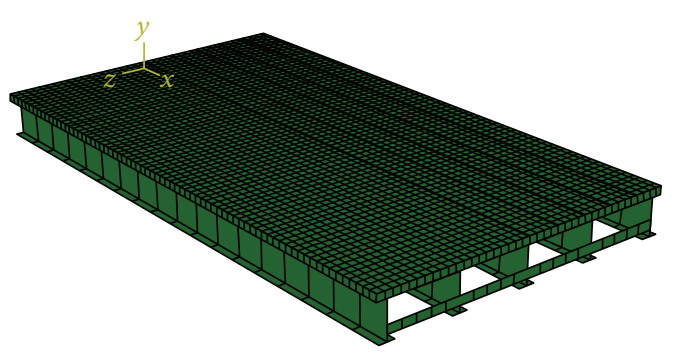

(b) 5 girders

FIGURE 5: Finite element model of the composite bridges with CFRP deck.

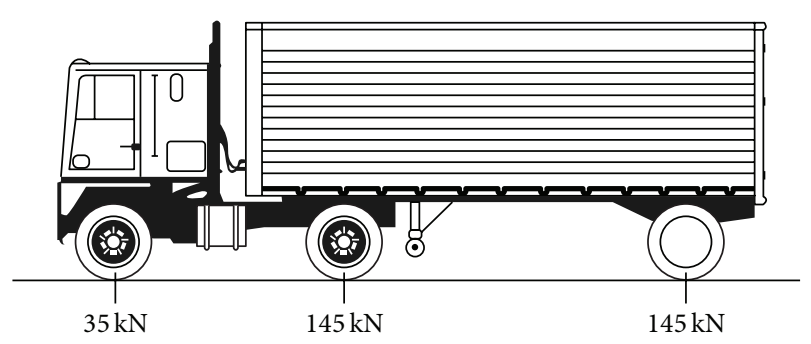

FIgUre 6: AASHTO-type HS20.

3.2. Loading Configurations. The applied loadings correspond to the tire loads of standard AASHTO-type multiaxle truck HS-20, as shown in Figure 6. Three directions of moving trucks are considered: single lane and dual lane with the same traffic direction and dual lane with opposite traffic direction.

The dynamic behaviors of the composite bridges are studied systematically by means of FE techniques performed in (semi)discretisation in spatial coordinates which is applicable to any type of structure, including the nonlinear type of behavior [13]. As a result, a discrete $N$-degree of freedom $(N-$ DOF) system of equations is obtained:

$$
M \ddot{d}+C \dot{d}+K d=f(t),
$$

where $M, C$, and $K$ are the mass, damping, and stiffness matrices, respectively. $f(t)$ is the load vector (from the moving loads), $d$ is the vector of nodal displacements, $\dot{d}$ is the vector of velocity, and $\ddot{d}$ is the vector of acceleration.

In order to integrate (1) with respect to time, generally a modal analysis and reduction leading to a reduced number of significant eigenmodes $n \ll N$ are performed, arriving at uncoupled equations which are integrated by standard time integration techniques such as by $\beta$-Newmark method. One simplest procedure to represent the load train is to apply load pulse time history for each node, depending on the time of arrival and discretisation. Therefore, in order to simulate the moving load, one may apply forces and moments as function of time to all nodes of the FE model of the whole structure. As shown in Figure 7, a concentrated force moves with velocity $V$ from node 1 to node $n$ of the beam which is composed of $n$ nodes and $n-1$ elements.
When a beam is subjected to a concentrated force, $P$, the forces on all nodes of other beams are equal to zero. The value of the force at the node in the element that is subjected to the concentrated force is a function of time, as shown in Figure 8.

Ignoring moments at each end of each element (neglecting $f_{2}^{(s)}(t)$ and $f_{4}^{(s)}(t)$ in Figure 8), a simple linear interpolation for the forces would allow the whole procedure to be generalized much more easily, as shown in the following [14] (Figure 9):

$$
\begin{gathered}
f_{1}^{(s)}(t)=P\left(1-\frac{x}{l}\right), \\
f_{3}^{(s)}(t)=P\left(\frac{x}{l}\right) .
\end{gathered}
$$

The time $(t)$ during which the concentrated force moves with velocity $V$ from node 1 to node $i$ of the beam can be found from the following equation:

$$
t_{i}=\frac{(i-1) \Delta x}{V}, \quad i=1,2, \ldots, n,
$$

where $\Delta x$ is the element length $\left(x_{i}-x_{i-1}\right)$, and $V$ is the train velocity.

3.3. Verification of the Finite Element Model. In order to verify the accuracy of the FE model of the composite bridges, equations for calculating the natural frequency of the bridge, introduced by Biggs and Suer [15], are employed. The equations are shown below:

$$
f=\lambda^{2} f_{s b}
$$

where $\lambda=\{1$ for simple beam, 1.25 for pinned-clamped beam, and 1.5 for clamped-clamped beam\}. Consider

$$
f_{s b}=\frac{\pi}{2 L^{2}} \sqrt{\frac{E_{b} I_{b} g}{w}}
$$

where $L=$ the span length, $g=$ acceleration due to gravity, $E_{b} I_{b}=$ flexural rigidity of the composite steel girder, and $w=$ the weight per unit length of the composite steel girder.

From literature reviews, (4) and (5) are sufficiently accurate for calculating the natural frequency of a simply supported one-span bridge [16]. Therefore, by using (4) and (5), 


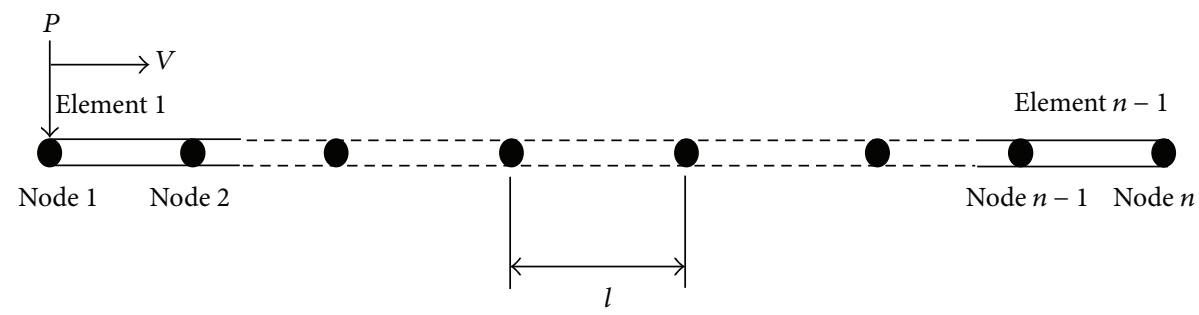

Figure 7: A beam subjected to a concentrated force, $P$, moving with velocity, $V$.

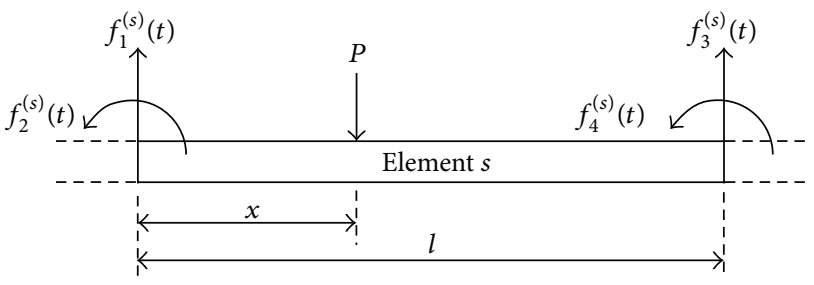

FIGURE 8: The equivalent forces of element $s$ subjected to a concentrated force $P$.

the natural frequency of the bridge can be obtained. Thereafter, natural frequency analyses of the FE model of the composite bridge have been carried out. Comparison of natural frequencies of the bridges is shown in Table 3. From the results, it can be seen that results from the FE models show good agreement with Biggs's equations. This implies that the accuracy of the FE model of the composite bridges used in this study is acceptable.

\section{Case Studies and Analysis Results}

4.1. Dynamic Analyses of Unstrengthened Composite Bridges under Moving Loads. In this part, dynamic analyses of unstrengthened composite bridges under various directions of moving trucks have been carried out in order to determine the direction of moving truck which gives the maximum response. The passing directions investigated in this study were single lane and dual lane with the same traffic direction and dual lane with opposite traffic direction, as shown in Figure 10.

Furthermore, the effect of the number of steel girders on the dynamic response was also investigated in this study. A constant truck speed was assumed at $80 \mathrm{~km} / \mathrm{hr}$. By performing FE simulation, the dynamic response of the composite bridges was obtained in terms of displacement and stress. It was found that maximum responses obtained from all FE analyses occurred at midspan of the bridge. The patterns of responses, that is, stress and displacement, are similar for all cases of moving truck, as shown in Figure 11. The dynamic responses for all cases are summarized in Table 4.

From Table 4, it can be seen that the maximum responses of composite bridges occur for the case of dual lane with the same traffic direction and dual lane with opposite traffic
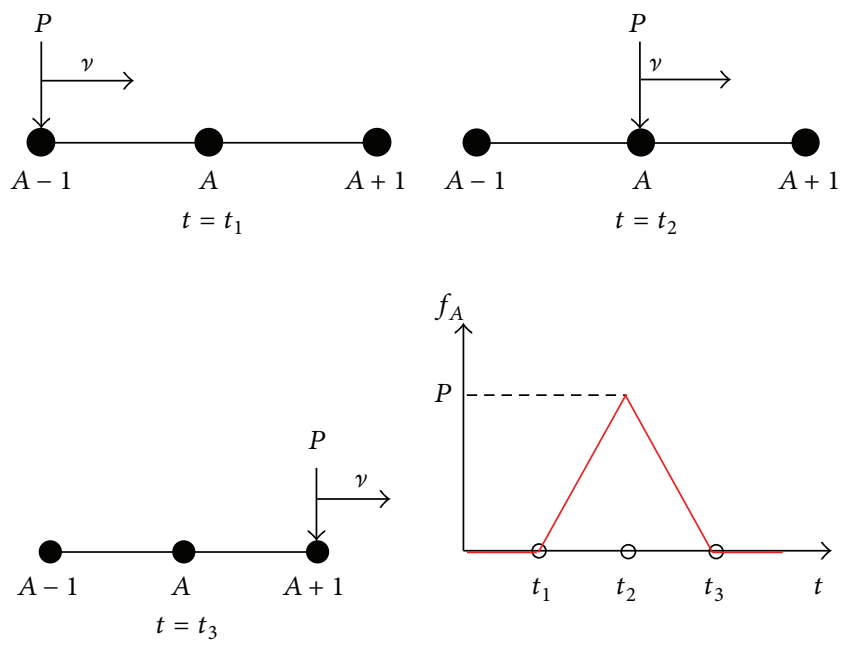

FIGURE 9: Definition of load at node $A$ for moving load $P$ in the finite element model.

direction for both the 3-girder bridge and the 5-girder bridge. For the case of the 3-girder bridge, the deflection response and the stress response increase about $11 \%$ and $13 \%$, respectively, compared to the single lane scenario due to the increase in truck weight on the bridge. For the case of the 5-girder bridge, the deflection response and stress response slightly increase, about $4.3 \%$ and $2.2 \%$, respectively, compared to the single lane case. Figure 12 depicts the graphical comparison of the results. The small increment of dynamic responses for the case of the 5-girder bridge is due to the increase in the bridge stiffness. Therefore, based on the above studies, dual lane with opposite traffic direction of moving trucks is adopted for further investigation.

4.2. Effect of CFRP Strengthening on the Dynamic Response of Undamaged Composite Bridges. In this part of the study, CFRP has been applied to strengthen undamaged composite bridges. From the results of Section 4.1, the moving truck load in dual lane with opposite traffic direction was applied into the FE model in order to investigate the effect of CFRP strengthening on the dynamic and fatigue responses of the composite bridge. Dynamic responses were measured in terms of stress and displacement responses, whereas fatigue response was evaluated based on fatigue response formulae 

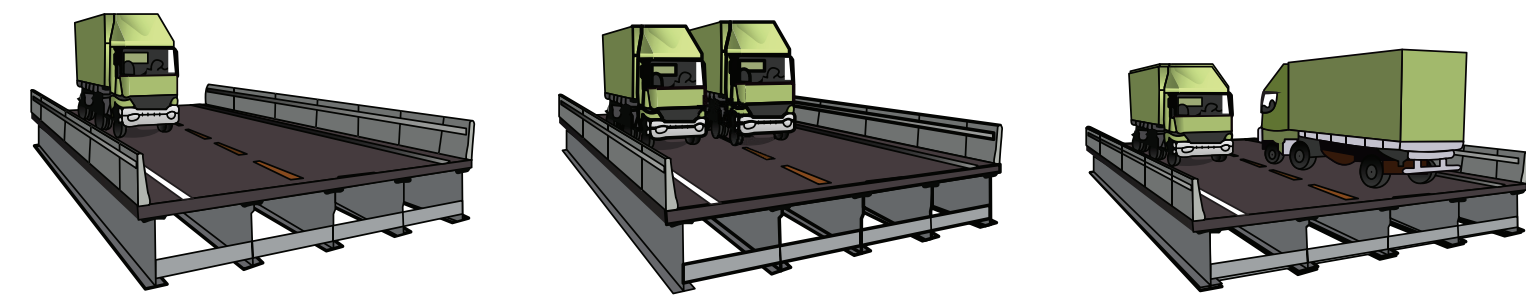

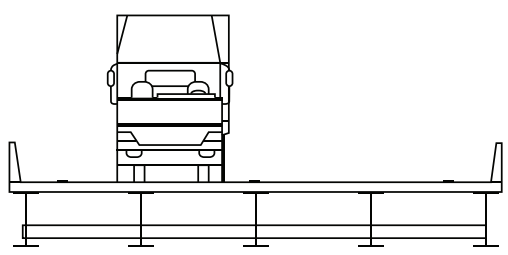

(a) Single lane

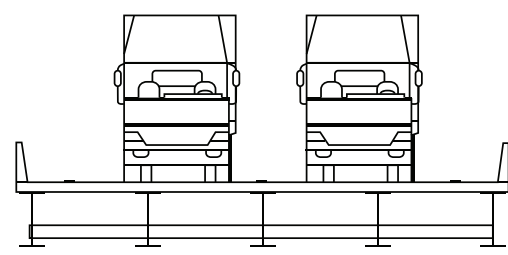

(b) Dual lane with the same traffic direction

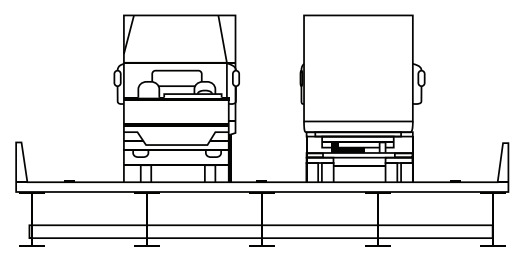

(c) Dual lane with opposite traffic direction

FIGURE 10: Passing directions of moving trucks.

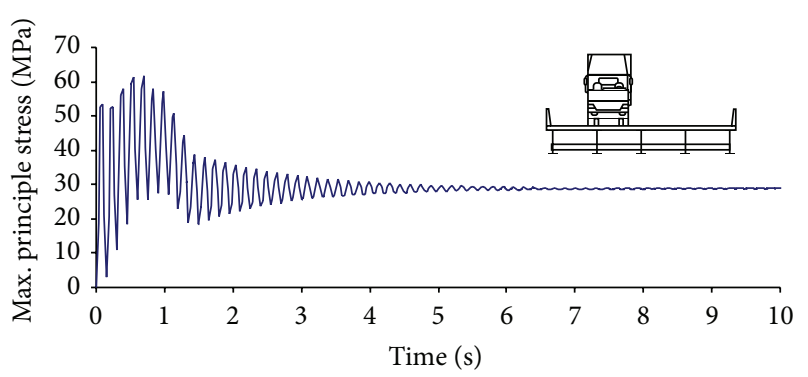

(a) Stress time history

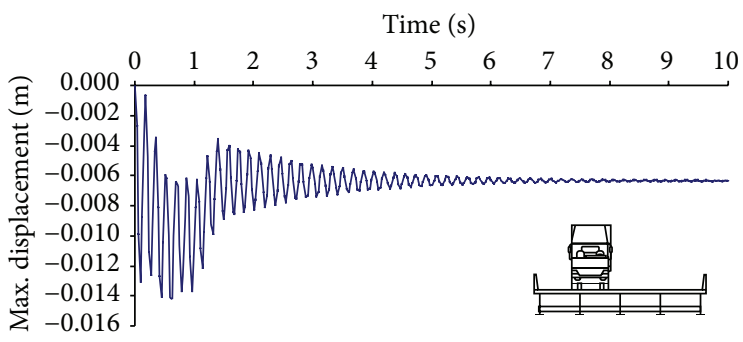

(b) Displacement time history

FIgURE 11: An example of dynamic responses extracted from the FE analysis.

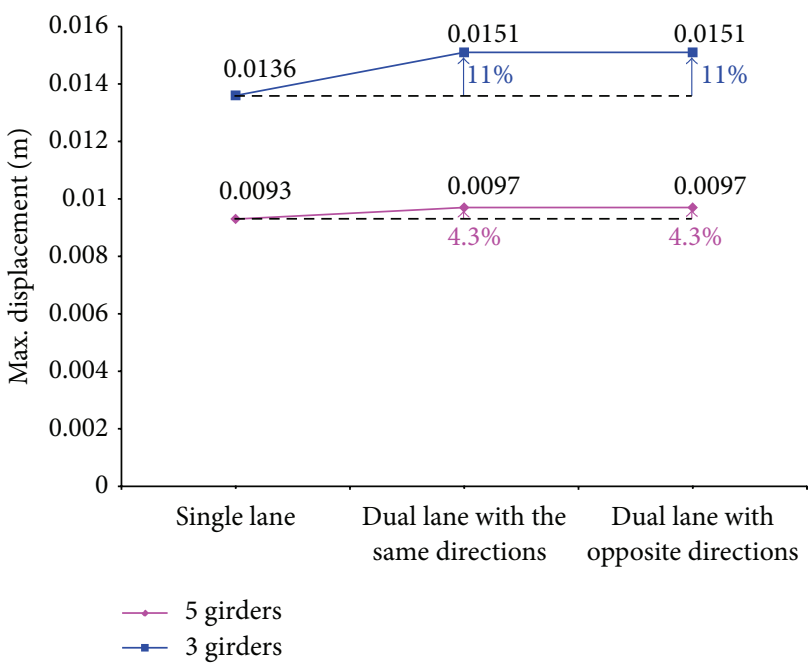

(a) Maximum displacement versus traffic direction

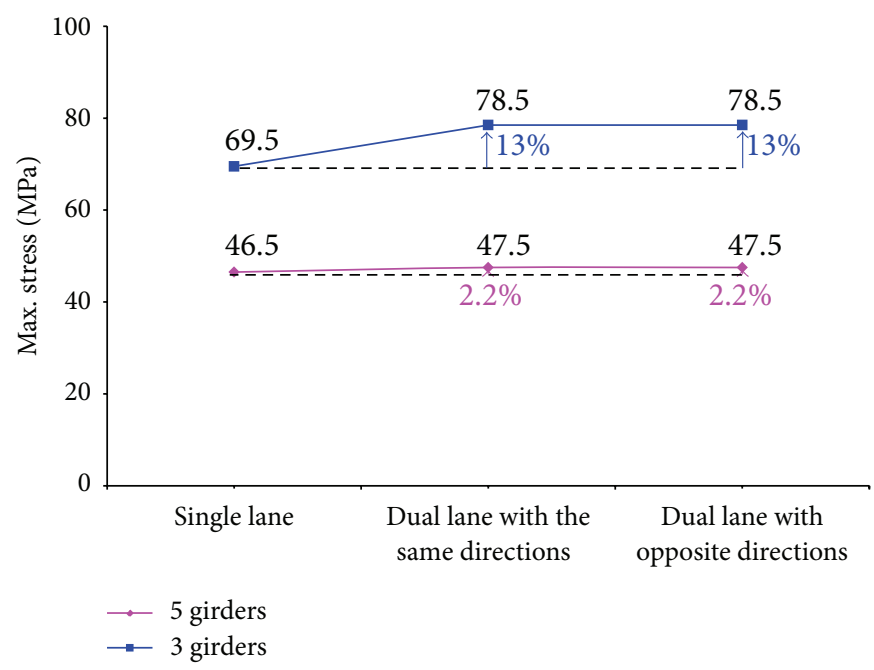

(b) Maximum stress versus traffic direction

FIGURE 12: Schematic of dynamic responses of unstrengthened composite bridges. 
TABLE 3: A comparison of natural frequency of the bridges.

\begin{tabular}{llccc}
\hline \multirow{2}{*}{$\begin{array}{l}\text { Number of steel } \\
\text { girders }\end{array}$} & Type of composite bridges & \multicolumn{2}{c}{ Natural frequency (Hz) } & From FE model \\
\hline 3 & $\begin{array}{l}\text { Unstrengthened/strengthened } \\
\text { with CFRP sheets } \\
\text { Strengthened with CFRP deck }\end{array}$ & 7.894 & 7.794 & 1.27 \\
\hline 5 & $\begin{array}{l}\text { Unstrengthened/strengthened } \\
\text { with CFRP sheets } \\
\text { Strengthened with CFRP deck }\end{array}$ & 10.476 & 10.423 & 0.51 \\
\hline
\end{tabular}

TABLE 4: Dynamic responses of unstrengthened composite bridges.

\begin{tabular}{llcr}
\hline Number of steel girders & Direction of moving trucks & Max. deflection (m) & Max. principal stress (MPa) \\
\hline \multirow{3}{*}{3} & Single lane & 0.0136 & 69.5 \\
& Dual lane with the same directions & 0.0151 & 78.5 \\
& Dual lane with opposite directions & 0.0151 & 78.5 \\
\hline \multirow{3}{*}{5} & Single lane & 0.0093 & 46.5 \\
& Dual lane with the same directions & 0.0097 & 47.5 \\
& Dual lane with opposite directions & 0.0097 & 47.5 \\
\hline
\end{tabular}

(6) to (8) specified in AASHTO-LRFD design specifications. Consider

$$
y=\frac{A}{n(365)(\mathrm{ADTT})_{\mathrm{SL}}(\Delta F)_{n}^{3}},
$$

where $A=$ a constant value (for category $C=14.4 \times$ $\left.10^{11} \mathrm{MPa}^{3}\right), n=$ the number of stress range cycles per truck passage (obtained directly from the FE analysis), $(\Delta F)_{n}=$ the nominal fatigue resistance in which $(\Delta F)_{n} \geq(1 / 2)(\Delta F)_{\mathrm{TH}}$. Consider

$$
\begin{gathered}
(\Delta F)_{n}=\left(\frac{A}{N}\right)^{1 / 3}, \\
N=n(365)(y)(\mathrm{ADTT})_{\mathrm{SL}},
\end{gathered}
$$

where $N=$ the number of cycles, $(\Delta F)_{\mathrm{TH}}=$ the constant fatigue threshold (for category $C=69 \mathrm{MPa})$, and $(\mathrm{ADTT})_{\mathrm{SL}}=$ the average daily truck traffic in a single lane.

The process in obtaining the stress range and the number of stress range used in the fatigue response calculation begins with $\mathrm{FE}$ analysis of the studied bridge to get the time response. By using rainflow counting method, the stress range and the number of cycles are obtained from the time response and shown as a stress range histogram. After extracting both the stress range and the number of stress cycles using the above process, the fatigue life of the composite bridge can be evaluated using (8). Full results of the FE analyses are summarized in Table 5.

From Table 5, it can be seen that midspan deflections of both the undamaged 3-girder bridge and the 5-girder bridge have been reduced after being strengthened by CFRP. By using CFRP sheets, the midspan deflections reduced from $0.015 \mathrm{~m}$ to $0.0134 \mathrm{~m}$ (about $10.7 \%$ ) and from $0.0097 \mathrm{~m}$ to $0.0082 \mathrm{~m}$ (about 15.5\%) for the 3-girder and the 5-girder composite bridges, respectively. Moreover, if the concrete deck is replaced by a CFRP deck, the reductions of midspan deflections of both the composite bridges are about $34.7 \%$ and $20.6 \%$, respectively. The reduction of midspan deflection is due to the increase in the bridge stiffness after attaching CFRP to the steel girders. Figure 13 illustrates graphical comparison of the results.

From the results of midspan stress, one can say that reduction of maximum stress occurring at midspan leads to an increase in the fatigue life of the composite bridge. The results in Table 5 show that, by using CFRP sheets, the fatigue lives increase from $25 \times 10^{6}$ cycles to $38.87 \times 10^{6}$ cycles (about 1.6 times) and from $112.24 \times 10^{6}$ cycles to $200.39 \times 10^{6}$ cycles (about 1.8 times) for the 3 -girder and the 5-girder composite bridges, respectively. If CFRP deck is used, the fatigue lives of both the composite bridges increase about 11 times and 5.1 times, respectively. It can be seen that, by reducing the weight of the superstructures, the fatigue life of the composite bridges can be increased. Therefore, from the results of both midspan deflection and fatigue response of the composite bridges, it can be concluded that CFRP material can be used to improve the fatigue life of composite bridges.

4.3. Effect of CFRP Strengthening on Dynamic Response of Damaged Composite Bridge. For the case of damaged composite bridge, two through-thickness crack sizes, $3 \mathrm{~mm}$ and $6 \mathrm{~mm}$ in depth (about 7.5\% and 15\% of the total flange depth), were assumed at midspan of the steel girdersas shown in Figure 14. At a small region, approximately less than ten times the crack tip opening, a fine mesh was modeled to ensure accuracy of the results. In a large strain analysis, an absolute sharp crack tip should not be adopted. Therefore an initial small notch radius was defined at $0.03 \mathrm{~mm}$.

The studied bridges were then analyzed under dual lane configuration with opposite direction of moving trucks. Dynamic responses of the composite bridge were measured 
TABLE 5: Full results of FE analyses of undamaged composite bridges.

\begin{tabular}{llccc}
\hline Number of steel girders & Type of composite bridges & $\begin{array}{c}\text { Midspan deflection } \\
(\mathrm{m})\end{array}$ & $\begin{array}{c}\text { Max. principal stress } \\
(\mathrm{MPa})\end{array}$ & $\begin{array}{c}\text { Fatigue life }(N) \\
\left(\times 10^{6} \mathrm{cycles}\right)\end{array}$ \\
\hline \multirow{3}{*}{3} & Unstrengthened & 0.015 & 78.5 & 25.19 \\
& Strengthened with CFRP sheets & 0.0134 & 68 & 38.87 \\
& Strengthened with CFRP deck & 0.0098 & 35.5 & 47.5 \\
\hline \multirow{2}{*}{5} & Unstrengthened & 0.0097 & 39.5 & 278.13 \\
& Strengthened with CFRP sheets & 0.0082 & 27.5 & 200.39 \\
\hline
\end{tabular}

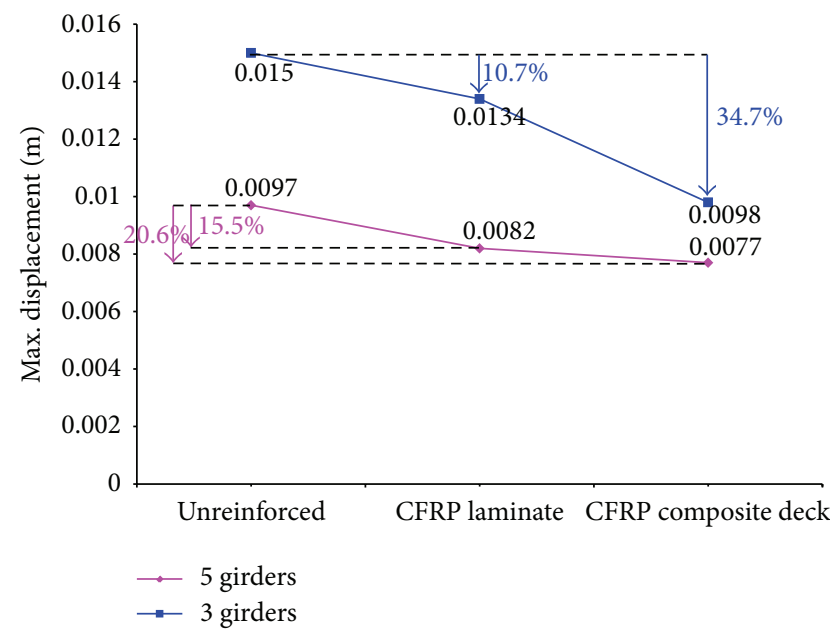

(a) Maximum displacement versus traffic direction

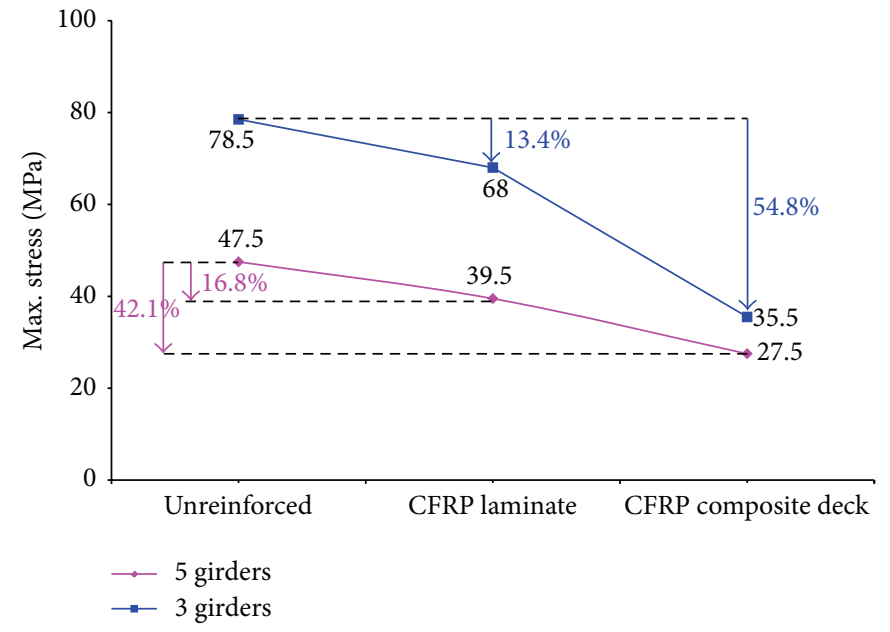

(b) Maximum stress versus traffic direction

FIGURE 13: Schematic of dynamic responses of undamaged composite bridges.

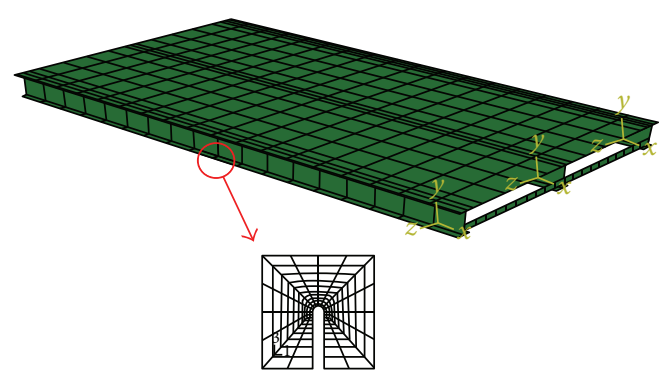

FIGURE 14: Finite element meshes in the crack tip region.

in terms of stress and displacement responses, whereas fatigue response was evaluated based on fatigue response formulae (8) specified in the AASHTO-LRFD design specifications. Full results of the FE analyses are summarized in Tables 6 and 7.

From Tables 6 and 7, strengthening the bridge by attaching CFRP sheets to the bottom flanges of the damaged steel girders can reduce midspan deflections from $0.0171 \mathrm{~m}$ to 0.0155 (about 9.4\%) and from $0.0107 \mathrm{~m}$ to $0.0094 \mathrm{~m}$ (about $12.1 \%$ ) for the 3-girder and the 5-girder composite bridges, respectively. However, when the concrete deck was replaced by a CFRP deck, the midspan deflection was even smaller than using CFRP sheets. The reductions of midspan deflections of both the composite bridges are about $28.7 \%$ and $18.7 \%$, respectively.

After introducing initial cracks into the steel girders, the fatigue lives of the bridges were dramatically reduced from $25.19 \times 10^{6}$ cycles to $1.64 \times 10^{6}$ cycles (or about 15.31 times) and from $112.24 \times 10^{6}$ cycles to $7.23 \times 10^{6}$ cycles (or about 15.52 times) for the 3-girder and the 5-girder composite bridges, respectively. Strengthening the composite bridge not only reduced the midspan deflection but also increased the fatigue life of the bridge. The results from the FE analyses show that, for the case of a $3 \mathrm{~mm}$ crack in the 3-girder bridge (see Table 6), the fatigue lives increased from $1.64 \times 10^{6}$ cycles to $3.5 \times 10^{6}$ cycles (about 2.13 times) and from $1.64 \times 10^{6}$ cycles to $8.32 \times 10^{6}$ cycles (about 5.07 times) when strengthened by CFRP sheets and CFRP deck, respectively. The same trend on the results can also be observed for the remaining cases. The fatigue lives of the studied bridges were further reduced when the size of the initial crack was increased to $6 \mathrm{~mm}$ (see Table 7). A reduction in the fatigue lives by a factor as large as two was found in this study. Again, with the help of CFRP, both the fatigue life and the deflection response of the bridge can be improved. 
TABLE 6: Full results of FE analyses of damaged (with $3 \mathrm{~mm}$ crack) composite bridges.

\begin{tabular}{llccc}
\hline Number of steel girders & Type of composite bridges & $\begin{array}{c}\text { Midspan deflection } \\
(\mathrm{m})\end{array}$ & $\begin{array}{c}\text { Max. principal stress } \\
(\mathrm{MPa})\end{array}$ & $\begin{array}{c}\text { Fatigue life }(N) \\
\left(\times 10^{6} \mathrm{cycles}\right)\end{array}$ \\
\hline \multirow{3}{*}{3} & Damaged and unstrengthened & 0.0171 & 92.8 & 1.64 \\
& Damaged and strengthened with CFRP sheets & 0.0155 & 81 & 3.5 \\
& Damaged and strengthened with CFRP deck & 0.0122 & 57.8 & 5.32 \\
\hline \multirow{2}{*}{5} & Damaged and unstrengthened & 0.0107 & 56.1 & 7.23 \\
& Damaged and strengthened with CFRP sheets & 0.0094 & 38.3 & 12.15 \\
\hline
\end{tabular}

TABLE 7: Full results of FE analyses of damaged (with $6 \mathrm{~mm}$ crack) composite bridges.

\begin{tabular}{|c|c|c|c|c|}
\hline Number of steel girders & Type of composite bridges & $\begin{array}{l}\text { Midspan deflection } \\
(\mathrm{m})\end{array}$ & $\begin{array}{c}\text { Max. principal stress } \\
(\mathrm{MPa})\end{array}$ & $\begin{array}{c}\text { Fatigue life }(N) \\
\left(\times 10^{6} \text { cycles }\right)\end{array}$ \\
\hline \multirow{3}{*}{3} & Damaged and unstrengthened & 0.0171 & 116.4 & 1.31 \\
\hline & Damaged and strengthened with CFRP sheets & 0.0155 & 101.8 & 1.75 \\
\hline & Damaged and strengthened with CFRP deck & 0.0122 & 63.2 & 5.91 \\
\hline \multirow{3}{*}{5} & Damaged and unstrengthened & 0.0107 & 67.3 & 5.26 \\
\hline & Damaged and strengthened with CFRP sheets & 0.0094 & 53.4 & 10.51 \\
\hline & Damaged and strengthened with CFRP deck & 0.0087 & 41.9 & 20.59 \\
\hline
\end{tabular}

\section{Conclusions}

A series of finite element analyses on dynamic and fatigue responses of composite bridges has been carried out in order to investigate the effect of CFRP strengthening on the overall behavior of composite bridges. Three-dimensional finite element models of composite bridges, that is, undamaged composite bridges with 3 and 5 girders, undamaged composite bridges with 3 and 5 girders strengthened by CRFP sheets and CFRP deck, and damaged composite bridges with 3 and 5 girders strengthened by CRFP sheets and CFRP deck, were modeled and analyzed under moving truck load. The dynamic behavior of undamaged bridges under moving trucks was first investigated. It was found that the maximum responses of composite bridges occur for the case of dual lane with the same traffic direction and dual lane with opposite traffic direction for both the 3-girder and the 5-girder bridges.

In order to investigate the effect of CFRP strengthening on the dynamic and fatigue response of the composite bridge, two types of CFRP strengthening techniques, CFRP sheets and CFRP deck, are adopted into the FE model. The results from the FE study can be summarized as follows.

(i) There are significant reductions in both the midspan deflection and the maximum stress after using CFRP as strengthening material. Respective percentage reductions as large as $34.6 \%$ and $54.8 \%$ were found in the analyses.

(ii) Comparing performance between the two techniques, CFRP deck appears to be more superior to CFRP sheets. Nevertheless, replacing concrete deck with CFRP deck is rather more complicated. Therefore careful justification should be conducted.

For the case of damaged composite bridges, revealing results from the FE analyses are obtained and are summarized below.

(i) After introducing initial cracks into the steel girders of the composite bridges, the fatigue life of the bridges dramatically reduced about 15 -folds.

(ii) Using CFRP to strengthen the damaged steel girders, the overall performance of the composite bridge can be improved. However, the level of improvement is not quite satisfactory since the fatigue life of the strengthened bridge is by far less than the undamaged/unstrengthened case. Therefore, if cracks are found during an inspection process, steel welding must be performed before strengthening the bridge by CFRP.

\section{Conflict of Interests}

The authors declare that there is no conflict of interests regarding the publication of this paper.

\section{Acknowledgments}

This project was supported by the Ministry of Education and the Thailand Research Fund (TRF) under Grant no. RMU5080073. The support is gratefully acknowledged. Special thanks go to senior lecturer Mr. Wiwat Sutiwipakorn for reviewing and correcting the English of this paper. 


\section{References}

[1] F. W. Klaiber, K. F. Dunker, T. J. Wipf, and W. W. Sanders, Methods of Strengthening Existing Highway Bridges, Transportation Research Board, Washington, DC, USA, 1987.

[2] R. A. Dorton and R. Reel, Methods for Increasing Live Load Capacity of Existing Highway Bridges, National Academy Press, Washington, DC, USA, 1997.

[3] R. Mayo, A. Nanni, S. Watkins, and M. Barker, "Strengthening of bridge G-270 with externally bonded CFRP sheets," in Proceedings of the 4th International Symposium on FRP for Reinforcement of Concrete Structures (FRPRCS '04), C. W. Dolan, S. H. Rizkalla, and A. Nanni, Eds., pp. 429-440, ACI, Baltimore, Md, USA, 1999.

[4] A. H. Al-Saidy, F. W. Klaiber, and T. J. Wipf, "Repair of steel composite beams with carbon fiber-reinforced polymer plates," Journal of Composites for Construction, vol. 8, no. 2, pp. 163-172, 2004.

[5] A. H. Al-Saidy, F. W. Klaiber, T. J. Wipf, K. S. Al-Jabri, and A. S. Al-Nuaimi, "Parametric study on the behavior of short span composite bridge girders strengthened with carbon fiber reinforced polymer plates," Construction and Building Materials, vol. 22, no. 5, pp. 729-737, 2008.

[6] R. Sen, L. Liby, G. Mullins, and K. Spillet, "Strengthening steel composites beams with CFRP laminates," in Proceedings of the 4th Materials Engineering Conference, K. P. Chong, Ed., pp. 1601-1607, ASCE, Washington, DC, USA, 1996.

[7] M. Tavakkolizadeh and H. Saadatmanesh, "Fatigue strength of steel girders strengthened with carbon fiber reinforced polymer patch," Journal of Structural Engineering, vol. 129, no. 2, pp. 186196, 2003.

[8] T. C. Miller, M. J. Chajes, D. R. Mertz, and J. N. Hastings, "Strengthening of a steel bridge girder using CFRP plates," Journal of Bridge Engineering, vol. 6, no. 6, pp. 514-522, 2001.

[9] M. Chiewanichakorn, A. J. Aref, and S. Alampalli, "Dynamic and fatigue response of a truss bridge with fiber reinforced polymer deck," International Journal of Fatigue, vol. 29, no. 8, pp. 1475-1489, 2007.

[10] W. Alnahhal, A. Aref, and S. Alampalli, "Composite behavior of hybrid FRP-concrete bridge decks on steel girders," Composite Structures, vol. 84, no. 1, pp. 29-43, 2008.

[11] AASHTO, ASSHTO LRFD Bridge Design Specifications, American Association of State Highway and Transportation Officials, Washington, DC, USA, 2007.

[12] ABAQUS Theory and User's Manual, Version 6.4, Hibbitt, Karlsson and Sorensen, Pawtucket, RI, USA, 2004.

[13] Y. B. Yang, J. D. Yau, and L. C. Hsu, "Vibration of simple beams due to trains moving at high speeds," Engineering Structures, vol. 19, no. 11, pp. 936-944, 1997.

[14] J. J. Wu, A. R. Whittaker, and M. P. Cartmell, "Use of finite element techniques for calculating the dynamic response of structures to moving loads," Computers and Structures, vol. 78, no. 6, pp. 789-799, 2000.

[15] J. M. Biggs and H. S. Suer, "Vibration measurements on simplespan bridges," Highway Research Board Bulletin, vol. 124, pp. 115, 1956.

[16] K. E. Barth and H. Wu, "Development of improved natural frequency equations for continuous span steel I-girder bridges," Engineering Structures, vol. 29, no. 12, pp. 3432-3442, 2007. 

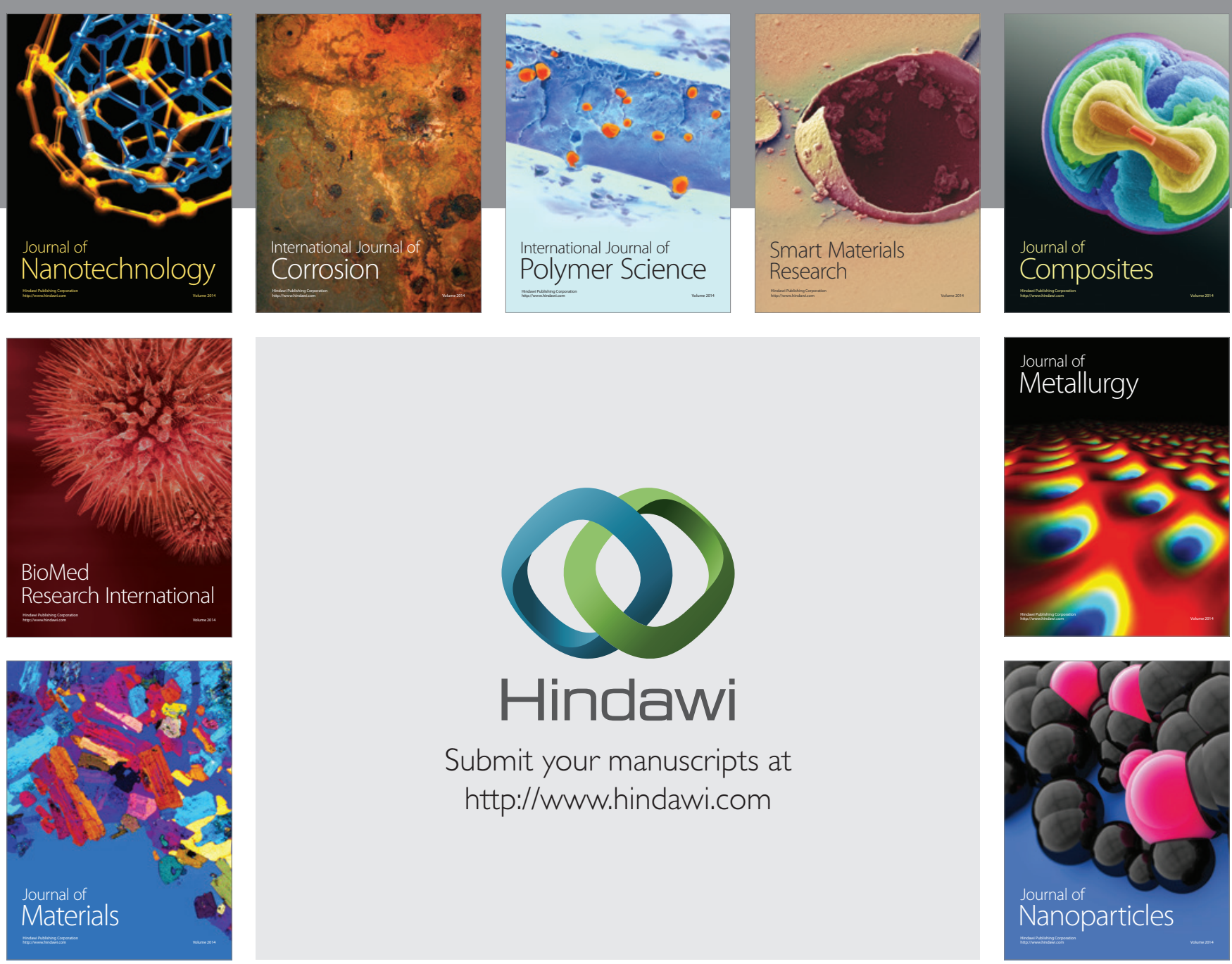

Submit your manuscripts at http://www.hindawi.com
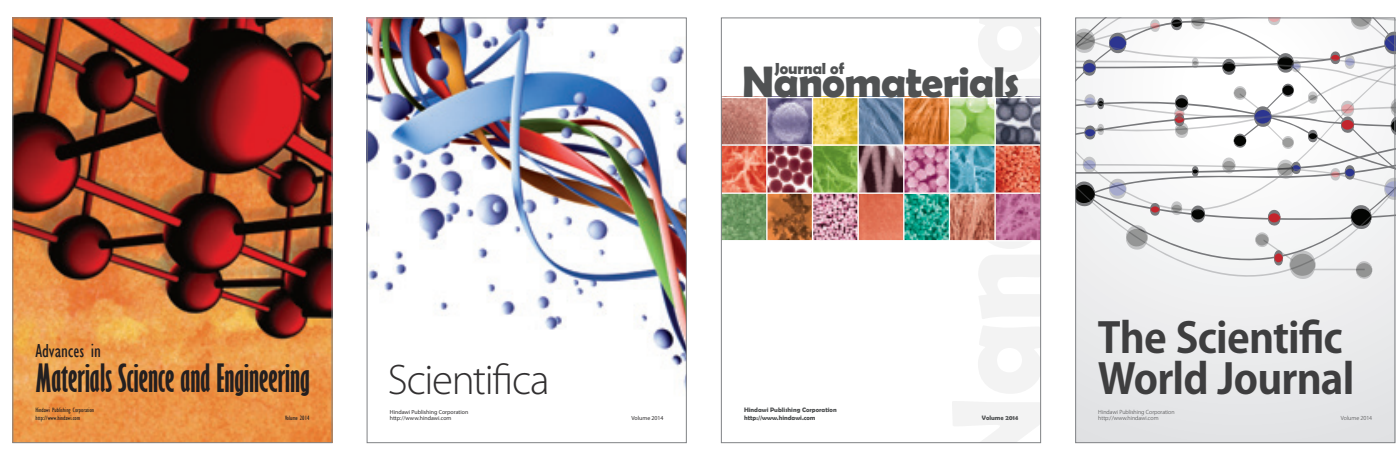

\section{The Scientific World Journal}
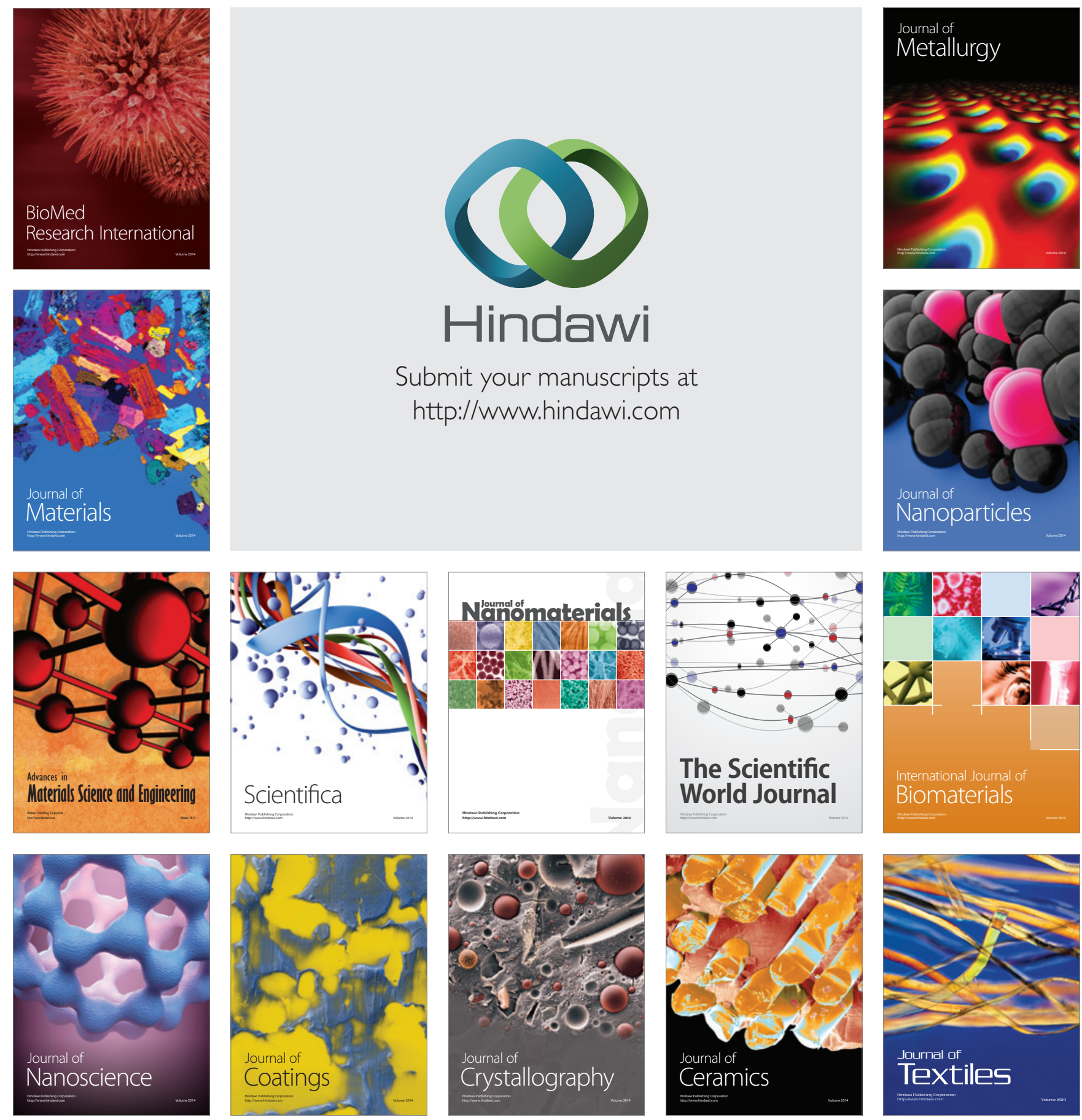